\title{
Implementation of Mini-Element for Solving Navier-Lame System with a New Boundary Condition
}

\author{
${ }^{1}$ Ouadie Koubaiti, ${ }^{2}$ Jaouad El-Mekkaoui and ${ }^{1}$ Ahmed Elkhalfi \\ ${ }^{1}$ Department of Mechanical Engineering, Faculty of Sciences and Technicals, \\ Sidi Mohammed Ben Abdellah University, \\ B.P. 2202 Route DImouzzer-Fes, Morocco \\ ${ }^{2}$ Department of Mathematics, Faculty Polydisciplinary of Beni-Mellal, \\ University of Sultan Moulay Slimane, Beni-Mellal, Morocco \\ kouba108@gmail.com
}

\begin{abstract}
The subject of our study is to apply the mixed finite element for solving the Navier-Lame system with a new boundary condition. We compare between mini-element method and the ordinary finite element by the other side. We calculate the displacement and its divergence simultaneously by using an extra unknown. We propose a new method of comparison, we calculate the rate $\alpha$ that is called a speed of convergence found by each of the both numerical methods, all this will be done by using the linear regression. An analytical example is used to validate the accuracy, convergence and robustness of the present mixed finite elements method for elasticity.
\end{abstract}

Key words: Navier-Lame system, new boundary condition, elasticity, mini-element, matrices computing, linear regression

\section{INTRODUCTION}

Elasticity theory is an important component of continuum mechanics and has had widely spread applications in science and engineering. This theory is primary for isotropic, linearly elastic materials subjected to small all governing equations in this theory are linear partial differential equations which means that the principle of superposition may be applied. The sum of individual solutions to the set of equations is also a solution to the equations. The aim of our project is to compare several numerical schemes, like the ordinary finite element and the mixed finite element to solve the Navier-Lame system with a new boundary condition generalizes the well known basis conditions, especially, the Dirichlet and the Neumann conditions. We computed the displacement $\mathrm{u}_{\text {spp }}$ for each methods. We program the two methods by using MATLAB and we needed to program again the functions to estimate the error between the computed solution and the reference one which is whether the analytical solution. When we calculate the solution of the system $-\mu \Delta \mathrm{u}-(\lambda+\mu) \nabla \nabla \cdot \mathrm{u}=\mathrm{f}$ on a given mesh, we get an approximate value $\mathrm{u}_{\mathrm{app}}$ of the solution. Of course, the finer will be the mesh and better will be the solution. We want to know for a schema numerical given how evolves the quality of the solution, according to the step of mesh. We know the theoretical relationship:

$$
\left\|\mathrm{u}-\mathrm{u}_{\text {app }}\right\| 1, \Omega=\beta \mathrm{h}^{\alpha}
$$

Where:

$\beta=$ The constant

$\mathrm{h}=$ The step of the mesh and

$\alpha=$ The speed of convergence

For the calculation of $\left\|\mathrm{u}-\mathrm{u}_{\text {app }}\right\| 1, \Omega$ we will use the the norm $\|\| 1,. \Omega$ which will be defined later. Knowing $\left\|\mathrm{u}-\mathrm{u}_{\mathrm{app}}\right\|$ $1, \Omega$ and the mesh step $h$ we want to calculate $\alpha$. For this, the simplest way to proceed is to go to the logarithm in Eq. 1. We get:

$$
\log \left(\left\|\mathrm{u}-\mathrm{u}_{\text {app }}\right\|\right) 1, \Omega=\log (\beta)+\alpha \cdot \log (\mathrm{h})
$$

Note that $\log \left(|| \mathrm{u}-\mathrm{u}_{\mathrm{app}}|| 1, \Omega\right)$ is an affine function of $\log$ (h) where the slope is $\alpha$. To find $\alpha$ we compute $\left(\left\|\mathrm{u}-\mathrm{u}_{\mathrm{app}}\right\|\right.$ $1, \Omega$ ) on different meshes, then we plot the graph of the $\log$ of $\left(\left\|\mathrm{u}-\mathrm{u}_{\mathrm{app}}\right\| 1, \Omega\right)$, according to the $\log$ of the step h.

We obtain the slope straight line. In practice the points are not exactly aligned to get the value of $\alpha$ in fact,

Corresponding Author: Ouadie Koubaiti, Department of Mechanical Engineering, Faculty of Sciences and Technicals, Sidi Mohammed Ben Abdellah University, B.P. 2202 Route Dimouzzer-Fes, Morocco 
we perform a linear regression in the least squares sense that is to say that we take for $\alpha$ the slope of the line that goes closer to all points.

Since, 2002, the study Alberty et al. (2002) entitled by MATLAB implementation of the finite element method in Elasticity, thanks to the researchers of this research J.Alberty, Kiel,

C. Carstensen, Vienna, SA Funken, Kiel and R.Klose that have a great contribution in computing the numerical solution that is the approximation of the exact solution which is the unknown in the Navier-Lame equation using the ordinary finite element method programmed by MATLAB. In fact, nobody has thought to apply the mixed finite element method to the equation Navier-Lame that will be the subject of our research. This study is based on the calculation of the numerical solution using the mixed finite element method (P1-bubble, P1) and to do this, we have to create another new unknown by setting $\psi$ equal to the divergence of the displacement, getting a couple of un-known $(\mathrm{u}, \psi)$ comparing the numerical results found in the stduy cited above mentioned in study (Alberty et al., 2002), we will prove that the new method is more accurate and efficient. We propose the numerical Method employs the mixed finite element (P1-bubble, P1) to calculate the numerical solution of the displacement and its discrete divergence to the following 2D Navier Lame problem.

\section{MATERIALS AND METHODS}

Governing equation: Linear elasticity is the mathematical study of how solid objects deform and become internally stressed due to prescribed loading conditions. Linear elasticity models materials as continua. Linear elasticity is a simplification of the more general nonlinear theory of elasticity and is a branch of continuum mechanics. The fundamental "linearizing" assumptions of linear elasticity are: infinitesimal strains or "small" deformations (or strains) and linear relationships between the components of stress and strain. In addition linear elasticity is valid only for stress states that do not produce yielding. These assumptions are reasonable for many engineering materials and engineering design scenarios. Linear elasticity is therefore, used extensively in structural analysis and engineering design, often with the aid of finite element analysis.

Let's consider $\Omega \subset \mathbb{R}^{2}$ be a bounded Lipschitz domain with boundary condition $\Gamma$ which will be presented in a new form that generalizes the Neumann and Dirichlet boundaries conditions. Given $f \in \mathrm{L}^{2}(\Omega), \mathrm{A}, \mathrm{B} \in \mathrm{L}^{\infty}(\Gamma)^{2 \times 2}$, $\mathrm{g} \in \mathrm{H}^{1}(\Gamma)$ and as well as the positive parameters $\lambda$ and $\mu$.

When solid objects are subjected to external or internal loads, they deform and led to stress. If the deformation of the solid is relatively small, linear relationships between the components of stress and strain are maintained. Consequently, linear elasticity theory is valid. In practice, linear elasticity theory is applicable to a wide range of natural and engineering materials and thus, extensively used in structural analysis and engineering design. The equation of Navier Lame below is governed as follows.

Solid object is deformed under the action of forces applied. A point in the solid, originally in $(\mathrm{x}, \mathrm{y})$, after sometime it will come into $(\mathrm{X}, \mathrm{Y})$, the vector $\mathrm{u}=\left(\mathrm{u}_{1}, \mathrm{u}_{2}\right)=(\mathrm{X}-\mathrm{x}, \mathrm{Y}-\mathrm{y})$ is called displacement. When the movement is small and the solid is elastic, then Hook's law gives a relationship between the stress tensor and the strain tensor. The $\sigma=\lambda \operatorname{tr}(\varepsilon) \mathrm{I}_{2}+2 \mu \varepsilon$ is the stress tensor, $\varepsilon=1 / 2\left(\nabla u+(\nabla U)^{\mathrm{T}}\right)$ is the strain tensor, $\mathrm{I}_{2}$ is the identity matrix, $\mu$ is the shear modulus (or rigidity) where, $\lambda$ is Lam's first parameter. Navier Lame equation is given by the law of conservation moment $\rho \mathrm{a}=$ divo with a is the acceleration and $\rho$ is the density of material on the other hand:

$$
\operatorname{div} \sigma=\lambda \operatorname{div}\left(\operatorname{tr}(\varepsilon) \mathrm{I}_{2}\right)+2 \mu \operatorname{div} \varepsilon
$$

Then, we have:

$$
\begin{gathered}
\operatorname{div} \sigma=\lambda \operatorname{div}\left(\operatorname{tr}(\varepsilon) \mathrm{I}_{2}\right)+\mu \operatorname{div}(\operatorname{gradu})+ \\
\mu \operatorname{div}(\text { gradu })^{t}
\end{gathered}
$$

With a simple calculation, we find that:

$$
\operatorname{div}\left(\operatorname{tr}(\varepsilon) \mathrm{I}_{2}\right)=\operatorname{div}(\operatorname{gradu})^{t}=\operatorname{grad}(\operatorname{div}(u))
$$

Then we get:

$$
\rho \mathrm{a}=\mu \Delta \mathbf{u}+(\lambda+\mu) \operatorname{grad}(\operatorname{divu})
$$

If the solid is in dynamic equilibrium then we have $\rho \mathrm{a}+\mathrm{f}=0$, $\mathrm{f}$ are the external forces applied to the solid. Finally, we find out the Eq. 7:

$$
\mathrm{f}=-\mu \Delta \mathrm{u}-(\lambda+\mu) \operatorname{grad}(\operatorname{divu})
$$

We refer the researcher to Sadd (2005), Timoshoenko and Goodier (1985) for more information of the elasticity problems. We create a new unknown $\psi=\nabla . u=$ $\partial_{\mathrm{u} 1} / \partial_{\mathrm{x}}+\partial_{\mathrm{u} 2} / \partial_{\mathrm{y}}$ is equal to divergence of the displacement. The Eq. 8 of Navier-Lame become:

$$
\left\{\begin{array}{c}
-\mu \Delta \mathrm{u}-(\lambda+\mu) \nabla \psi=\mathrm{fin} \Omega \\
\psi-\nabla \cdot \mathrm{u}=0 \text { in } \Omega \\
\mathrm{Au}+\mathrm{B}\left(\mu \frac{\partial \mathrm{u}}{\partial \mathrm{n}}+\lambda \nabla \cdot \mathrm{un}\right)=\mathrm{g} \text { on } \Gamma
\end{array}\right.
$$


Our mathematical model is the Navier-Lame system with a new boundary condition noted $\mathrm{C}_{\mathrm{A}, \mathrm{B}}$ such as $\mathrm{A}$ is called Dirichlet matrix and B is Neumann matrix we assume the following two hypothesis on matrix functions $\mathrm{A}$ and $\mathrm{B}$. For all $\mathrm{x} \in \Gamma$ the matrix $\mathrm{B}(\mathrm{x})$ is an invertible matrix. Likewise, there are two strictly positive constants $\alpha$ and $\beta$ such that:

$$
\alpha u . v<\mathrm{B}^{-1} \text { Au.v }<\beta u . v \forall \mathrm{u}, \mathrm{v} \in \mathrm{H}^{1}(\Omega)
$$

With ||$.|| \mid$ is a matrix norm that will be defined below. If $\|\mathrm{A}\|\|\|\|\mathrm{B}\|$, then $\mathrm{C}_{\mathrm{A}_{\mathrm{B}}}$ is the Neumann boundary condition and if $\|\mathrm{B}\|||\||| \mathrm{A}\| \mid$ then $\mathrm{C}_{\mathrm{A}, \mathrm{B}}$ is the Dirichlet boundary. We need functional spaces and norms:

$$
\begin{gathered}
\mathrm{h}^{1}(\Omega)=\left\{\mathrm{u}: \Omega \rightarrow \mathrm{u} \backslash \mathrm{u}, \frac{\partial \mathrm{u}}{\partial \mathrm{x}}, \frac{\partial \mathrm{u}}{\partial \mathrm{y}} \in \mathrm{L}^{2}(\Omega)\right\} \\
\mathrm{v}(\Omega)=\mathrm{H}^{1}(\Omega)=\left[\mathrm{h}^{1}(\Omega)\right]^{2} \\
\mathrm{M}(\Omega)=\mathrm{L}_{0}^{2}(\Omega)=\left\{\mathrm{q} \in \mathrm{L}^{2}(\Omega) / \int_{\Omega} \mathrm{q}=0\right\} \\
\|v\| 1, \Omega=\left\{\int_{\Omega} \nabla \mathrm{u}: \nabla \mathrm{ud} \Omega+\int_{\Omega} \mathrm{v} \cdot \mathrm{vd} \Omega\right\}^{\frac{1}{2}} \\
\|\mathrm{v}\| 0, \Omega=\left\{\int_{\Omega} \mathrm{v} \cdot \mathrm{vd} \Omega\right\}^{\frac{1}{2}} \\
\|\mathrm{~A}\||\max | \mathrm{a}_{\mathrm{i}, \mathrm{j}} \mid \mathrm{i}=1.2, \mathrm{j}=1.2
\end{gathered}
$$

The variational formulation of the Navier-Lame problem (Eq. 8) is as follows. Find $(\mathrm{u}, \psi) \in \mathrm{V}(\Omega) \times \mathrm{M}(\Omega)$ such that:

$$
\left\{\begin{aligned}
\int_{\Omega} \mu \nabla \mathrm{u}: \nabla \mathrm{ud} \Omega+\int_{\Gamma} \mathrm{B}^{-1} \mathrm{Au} \cdot \mathrm{vd} \Gamma \\
+\int_{\Gamma} \mu \psi \mathrm{n} \cdot \mathrm{vd} \Gamma+\int_{\Omega}(\lambda+\mu) \psi \nabla \cdot \mathrm{ud} \Omega \\
\quad=\int_{\Omega} \mathrm{f} \cdot \mathrm{ud} \Omega+\int_{\Gamma} \mathrm{B}^{-1} \mathrm{~g} \cdot \mathrm{vd} \Gamma \\
\int_{\Omega}(\lambda+\mu) \mathrm{q} \nabla \cdot \mathrm{ud} \Omega-\int_{\Omega}(\lambda+\mu) \psi \mathrm{qd} \Omega=0
\end{aligned}\right.
$$

The weak formulation (Eq. 16) may be restated as: Find $(\mathrm{u}, \psi) \in \mathrm{V}(\Omega) \times \mathrm{M}(\Omega)$ :

$$
\left\{\begin{array}{l}
\mathrm{a}(\mathrm{u}, \mathrm{v})+\mathrm{b}_{\Gamma}(\mathrm{v}, \Psi)=\mathrm{L}(\mathrm{v}) \forall \mathrm{u} \in \mathrm{V}_{0}(\Omega) \\
\mathrm{b}(\mathrm{u}, \mathrm{q})-\mathrm{d}(\Psi, \mathrm{q})=0 \forall_{\mathrm{q}} \in \mathrm{M}(\Omega)
\end{array}\right.
$$

With the bilinear forms:

$$
\left\{\begin{array}{c}
\mathrm{a}(\mathrm{u}, \mathrm{v})=\int_{\Omega} \mu \nabla \mathrm{u}: \nabla \mathrm{ud} \Omega+\int_{\Gamma} \mathrm{B}^{-1} \mathrm{Au} \cdot \mathrm{vd} \Gamma \\
\mathrm{b}(\mathrm{v}, \mathrm{q})=\int_{\Omega}(\lambda+\mu) \mathrm{q} \nabla \cdot \mathrm{ud} \Omega \\
\mathrm{b} \Gamma(\mathrm{v}, \mathrm{q})=\mathrm{b}(\mathrm{v}, \mathrm{q})+\int_{\Gamma} \mu \mathrm{qn} \cdot \mathrm{vd} \Gamma \\
\mathrm{d}(\psi, \mathrm{q})=\int_{\Omega}(\lambda+\mu) \Psi \mathrm{qd} \Omega \\
\mathrm{L}(\mathrm{v})=\int_{\Omega} \mathrm{f} \cdot \mathrm{vd} \Omega+\int_{\Gamma} \mathrm{B}^{-1} \mathrm{~g} \cdot \mathrm{vd} \Gamma
\end{array}\right.
$$

The bilinear forms defined in Eq. 18 check all the assumptions of theorem 3.1 by Ciarlet et al. (2003) and all the results that are missing to show the existence and uniqueness of the weak solution $(\mathrm{u}, \psi)$ of the system (Eq. 17), exist in the section 4 by EL-Mekkaoui et al. (2013).

Mixed finite element: The term mixed method was first used in the 1960's to describe finite element methods in which both stress and displacement fields are approximated as primary variables.

In numerical analysis, the mixed finite element method also known as the hybrid finite element method is a type of finite element method in which extra independent variables are introduced as nodal variables during the discretization of a partial differential equation problem. The extra independent variables are constrained by using Lagrange multipliers. To be distinguished from the mixed finite element method usual finite element methods that do not introduce such extra independent variables are also called irreducible finite element methods. The mixed finite element method is efficient for some problems that would be numerically ill-posed, if discretized by using the irreducible finite element method, one example of such problems is to compute the stress and strain fields in an almost incompressible elastic body (Zienkiewicz et al., 2013).

To apply the method of mixed finite element P1- bubble/P 1 for the variational problem (Eq. 17). We need some mathematical tools, then we us the approximation of the Standard Galerkin method for more explication we can see in the articles and books Girault and Raviart, (1981), Ern (2005), Boffi et al., 2013, Kellogg and Liu (1996), Yang (2002), Gatica (2014), Brezzi and Fortin (1991). Let's consider a uniform triangulation $T_{h}$ of the rectangular domain $\Omega$ where $h>0$ is the maximum diameter of all elements $K \in T_{h}$ and $T_{h}$ consists of triangles in two dimensions.

We assume that we have a sequence of triangulations $\left(\mathrm{T}_{\mathrm{h}}\right)_{\mathrm{h}} \mathrm{h} \rightarrow 0$. Let $\lambda_{1}{ }^{\mathrm{K}}, \lambda_{2}{ }^{\mathrm{K}}, \lambda_{2}{ }^{\mathrm{K}}$ be the barycenter coordinates with respect to a triangle $\mathrm{K} \mu^{\mathrm{K}}$ is the bubble function associated with the triangle $\mathrm{K}$ defined by $\mu^{\mathrm{K}}=\lambda_{1}{ }^{\mathrm{K}}$ $\lambda_{2}{ }^{\mathrm{K}} \lambda_{3}{ }^{\mathrm{K}}$ in $\mathrm{K}$ and equal to 0 else where. We define the 
discrete domain $\Omega_{\mathrm{h}}=\mathrm{U}_{\mathrm{k}=1}^{\mathrm{n}} \mathrm{T}_{\mathrm{k}} / \Omega$ and $\Omega_{\mathrm{h}}$ is closed if $\Omega$ is polygon then $\Omega_{\mathrm{h}}=\Omega$ and $\Gamma_{\mathrm{h}}=\partial \Omega_{\mathrm{h}}=\partial \Omega=\Gamma$ with $\beta k, \theta_{i}^{k} \in \square, \forall K \in T_{h}$ and $P_{1}(K)$ is the space of polynomials defined on the triangle $\mathrm{K}$ of the degree lower or equal to 1. The functions of $V_{h} \times M_{h}$ are not globally affine in all but only affine by piece.

On the other hand, they are generally continuous. The functions of the space are completely determined by their values in each of the mesh vertices. For the solution of an elasticity problem, the displacement/div-displacemet $(\mathrm{u} / \psi)$ finite element discretization are effective by Bathe (1996).

Let, $V_{h}$ be the finite element displacement interpolation space and $M_{h}$ be the finite element div-displacement interpolation space (corresponding to the spaces $\mathrm{V}(\Omega)$ and $\mathrm{M}=\mathrm{L}_{0}^{2}(\Omega)$ of the continuous problem. The functions of the space $V_{h}$ are completely determined by their values in each of the mesh vertices. Moreover, the dimension of the space $V_{h}$ is $N-n_{s}$ with $N$ is the overall number of vertices and $n_{s}$ the number of vertices on the boundaries. Then the mixed finite elements problem is like. We define the approached spaces as follow. For all $\left(\mathrm{u}_{\mathrm{h}}, \psi_{\mathrm{h}}\right) \in \mathrm{V}_{\mathrm{h}} \times \mathrm{M}_{\mathrm{h}} \subset \mathrm{V} \times \mathrm{M}$, we have:

$$
\begin{aligned}
& \varphi_{\mathrm{h}}=\sum_{\mathrm{i}=1}^{3} \alpha_{\mathrm{i}}^{\mathrm{k}} \lambda_{\mathrm{i}}^{\mathrm{k}}+\beta^{\mathrm{k}} \mu^{\mathrm{k}}(\mathrm{x}) \alpha_{\mathrm{i}}^{\mathrm{k}} \\
& \psi_{\mathrm{h}}=\sum_{\mathrm{i}=1}^{3} \theta_{\mathrm{i}}^{\mathrm{k}} \lambda_{\mathrm{i}}^{\mathrm{k}}, \forall \mathrm{K} \in \mathrm{T}_{\mathrm{h}}
\end{aligned}
$$

Let's see $\mathrm{k}\left(\mathrm{u}_{\mathrm{h}}, \psi_{\mathrm{h}}\right) \in \mathrm{V}_{\mathrm{h}} \times \mathrm{M}_{\mathrm{h}}$ :

$$
\left\{\begin{array}{l}
\mathrm{a}\left(\mathrm{u}_{\mathrm{h}}, \mathrm{v}_{\mathrm{h}}\right)+\mathrm{b}_{\Gamma}\left(\mathrm{v}_{\mathrm{h}}, \Psi_{\mathrm{h}}\right)=\mathrm{L}_{\mathrm{h}}\left(\mathrm{v}_{\mathrm{h}}\right) \\
\mathrm{b}\left(\mathrm{u}_{\mathrm{h}}, \mathrm{q}_{\mathrm{h}}\right)-\mathrm{d}_{\mathrm{h}}\left(\Psi_{\mathrm{h}}, \mathrm{q}_{\mathrm{h}}\right)=0
\end{array}\right.
$$

For all $v_{h} \in V_{h}$ and $q_{h} \in M_{h}$. Where:

$$
\begin{gathered}
a\left(u_{h}, v_{h}\right)=\int_{K} \mu \nabla u_{h} \cdot \nabla v_{h} d K+ \\
\int_{\Gamma_{h}} B^{-1} A u_{h}: v_{h} d \Gamma_{h} \\
b\left(v_{h}, q_{h}\right)=\int_{K}(\lambda+\mu) q_{h} \nabla \cdot v_{h} d K \\
b_{\Gamma}\left(v_{h}, q_{h}\right)=b\left(v_{h}, q_{h}\right)+\int_{\Gamma_{h}} \mu q_{h} n K \cdot v_{h} d \Gamma_{h} \\
d\left(\psi_{h}, q_{h}\right)=\int_{K}(\lambda+\mu) \psi_{h} q_{h} d K \\
L\left(v_{h}\right)=\int_{K} f \cdot v_{h} d K+\int_{\Gamma_{h}} B^{-1} g_{h} \cdot v_{h} d \Gamma_{h}
\end{gathered}
$$

With $\Gamma_{\mathrm{h}}=\Gamma$ ก $\partial \mathrm{K}$ and $\mathrm{n}_{\mathrm{k}}$ the normal on $\mathrm{K}$.
The existence and uniqueness of the solution of the mixed formulation (Eq. 20) is shown by using the continuity of the bilinear forms $\alpha$ on $V_{h} \times V_{h}, b_{T}$ on $V_{h} \times M_{h}$, $b$ on $V_{h} \times M_{h}$ and $d$ on $M_{h} \times M_{h}$ is clear by using the korn's inequality. On the other hand the coercivity of the bilinear form a on $\mathrm{V}_{\mathrm{h}}$ and $\mathrm{d}$ on $\mathrm{M}_{\mathrm{h}}$ is hold by using theirs coercivity on $V(\Omega)$ and $M(\Omega)$, respectively, since, $\mathrm{V}_{\mathrm{h}} \subset \mathrm{V}(\Omega)$. We can see the uniform infsup condition uniformly of the bilinear form b by Arnold et al. (1984) with respect to the mesh-size. We will prove that the uniform inf-sup condition for the bilinear form $b_{\Gamma}$ on $\mathrm{V}_{\mathrm{h}} \times \mathrm{M}_{\mathrm{h}}$, it means that we have to prove the existence of a constant $\partial>0$ independent of the meshsize as the following theorem clarifies.

Theorem 1: There exist $\partial>0$ such as:

$$
\begin{aligned}
& \forall \mathrm{q}_{\mathrm{h}} \in \mathrm{M}_{\mathrm{h}} \exists \mathrm{u}_{\mathrm{h}} \in \mathrm{V}_{\mathrm{h}}, \mathrm{u}_{\mathrm{h}} \neq 0 \\
& \mathrm{~b}_{\Gamma}\left(\mathrm{u}_{\mathrm{h}}, \mathrm{q}_{\mathrm{h}}\right) \geq \vartheta\left\|\mathrm{u}_{\mathrm{h}}\right\| 1, \Omega\left\|\mathrm{q}_{\mathrm{h}}\right\| 0, \Omega
\end{aligned}
$$

This theorem guarantee the verification of the condition inf_sup of the bilinear form $\mathrm{b} \Gamma$. It should be noted that for all $\mathrm{u}_{\mathrm{h}} \in \mathrm{V}_{\mathrm{h}}$ :

$$
\mathrm{b}_{\Gamma}\left(\mathrm{u}_{\mathrm{h}}, \mathrm{q}_{\mathrm{h}}\right)=\mathrm{b}\left(\mathrm{u}_{\mathrm{h}}, \mathrm{q}_{\mathrm{h}}\right)+\int_{\Gamma_{\mathrm{h}}} \mu \mathrm{q}_{\mathrm{h}} \mathrm{n}_{\mathrm{K}} \cdot \mathrm{v}_{\mathrm{h}} \mathrm{d} \Gamma_{\mathrm{h}}
$$

Proof: First we prove that the bilinear form $b$ verifies (Eq. 26) of theorem (Eq. 1). It is assumed that the triangulation. $T_{h}$ is uniformly regular. Let $q_{h} \in M_{h}$ be fixed $M_{h} \subset M$ and that the bilinear form $b$ satisfies the inf _ sup condition in $\mathrm{V} \times \mathrm{M}$, so that, there exist $u \in V$ and $b\left(u q_{h}\right) \geq$ $\beta\|\mathrm{u}\| 1, \Omega\left\|\mathrm{q}_{\mathrm{h}}\right\| \quad 0, \Omega$. With $\beta>0$ independent of $\mathrm{q}_{\mathrm{h}}$ but $\mathrm{u}$ depends of $q_{h}$. For this $u$ we have just show that $u_{h} \in V_{h}$ clarified:

$$
\begin{aligned}
& \mathrm{b}_{\Gamma}\left(\mathrm{u}_{\mathrm{h}}, \mathrm{q}_{\mathrm{h}}\right)=\mathrm{b}\left(\mathrm{u}, \mathrm{q}_{\mathrm{h}}\right) \\
& \left\|\mathrm{u}_{\mathrm{h}}\right\| 1, \Omega \leq \mathrm{c}\|\mathrm{u}\| 1, \Omega
\end{aligned}
$$

The relations (Eq. 28 and 29) are the subject of the lemma 2 that comes afterwards. Where, $c>0$ is independent of $q_{h}$ and $h$, indeed if (Eq. 28) are checked, so:

$$
\begin{gathered}
\mathrm{b}\left(\mathrm{u}_{\mathrm{h}}, \mathrm{q}_{\mathrm{h}}\right)=\mathrm{b}\left(\mathrm{u}, \mathrm{q}_{\mathrm{h}}\right) \geq \beta\|\mathrm{u}\| 1, \Omega\left\|\mathrm{q}_{\mathrm{h}}\right\| 0, \Omega \geq \\
\frac{\beta}{\mathrm{c}}\left\|\mathrm{u}_{\mathrm{h}}\right\| 1, \Omega\left\|\mathrm{q}_{\mathrm{h}}\right\| 0, \Omega
\end{gathered}
$$

Just take $_{\beta^{\prime}=\frac{\beta}{c}}$ otherwise, we can easily check that:

$$
\int_{\Gamma}|\mu q n . u| d \Gamma \leq \mathrm{c}^{\prime}|\mu|\|\mathrm{u}\| 1, \Omega\|\mathrm{q}\| 0, \Omega
$$


Then, $V_{h} \subset V$ and $M_{h} \subset M$ we obtain:

$$
\int_{\Gamma}|\mu q n . u| d \Gamma \leq \mathrm{c}^{\prime}\left|\mu_{\mathrm{h}}\right| \mid \mathrm{u}_{\mathrm{h}}\|1, \Omega\| \mathrm{q}_{\mathrm{h}} \| 0, \Omega
$$

Combining (Eq. 32 and 30) Moreover, we assume that $\mu \mathrm{qhn}: \mathrm{u}_{\mathrm{h}}$ adopts a negative sign, then we have:

$$
\mathrm{b}_{\Gamma}\left(\mathrm{u}_{\mathrm{h}}, \mathrm{q}_{\mathrm{h}}\right) \geq\left(\beta^{\prime}-\mathrm{c}^{\prime}\right) \mu\left\|\mathrm{q}_{\mathrm{h}}\right\| 0, \Omega\left\|\mathrm{u}_{\mathrm{h}}\right\| 1 \Omega
$$

If we suppose $\mu<\frac{\beta^{\prime}}{c^{\prime}}$ also we get $\vartheta_{0}=\left(\beta^{\prime}-c^{\prime}\right) \mu$, so, whatever the sign of $\mu q_{h}^{c^{\prime}} n$. $u_{h}$ we conclude that:

$$
\mathrm{b}_{\Gamma}\left(\mathrm{u}_{\mathrm{h}}, \mathrm{q}_{\mathrm{h}}\right) \geq \min \left(\vartheta_{0}, \beta^{\prime}\right)\left\|\mathrm{u}_{\mathrm{h}}\right\| 1, \Omega\left\|\mathrm{q}_{\mathrm{h}}\right\| 0, \Omega
$$

Just take $\vartheta=\min \left(\vartheta_{0}, \beta^{\prime}\right)$, it means that we answer the theorem (1):

Lemma 2: There exist $u_{h} \in V_{h}, c>0$ and we suppose that $u$ is fixed such as:

$$
\begin{gathered}
\mathrm{b}\left(\mathrm{u}_{\mathrm{h}}, \mathrm{q}_{\mathrm{h}}\right)=\mathrm{b}\left(\mathrm{u}, \mathrm{q}_{\mathrm{h}}\right) \forall \mathrm{q}_{\mathrm{h}} \in \mathrm{M}_{\mathrm{h}} \\
\left\|\mathrm{u}_{\mathrm{h}}\right\| 1, \Omega \leq \mathrm{c}\|\mathrm{u}\| 1, \Omega
\end{gathered}
$$

Proof: First we define the linear operator $R_{h} \in L\left(V, V_{h}\right)$, which verifies $\forall_{\mathrm{vh}} \in \mathrm{V}_{\mathrm{h}}, \exists ! \mathrm{v} \in \mathrm{V}$, so that, $\mathrm{R}_{\mathrm{h}} \mathrm{v}=\mathrm{v}_{\mathrm{h}}$. This operator is a projector of $V$ on $V_{b}$ it is well defined. Indeed Lax Milgram ensures the unique existence of the variational problem (Eq. 37) Find $v$ in $V$, so as:

$$
\int_{\Omega} \nabla\left(\mathrm{R}_{\mathrm{h}} \mathrm{v}-\mathrm{v}\right) \cdot \nabla \mathrm{v}_{\mathrm{h}} \mathrm{dx}=0, \forall \mathrm{v}_{\mathrm{h}} \in \mathrm{V}_{\mathrm{h}}
$$

If we take $v_{h}=R_{h} V$ in (Eq. 37), we obtain:

$$
\left\|\nabla \mathrm{R}_{\mathrm{h}} \mathrm{v}\right\|_{0}^{2}, \Omega=\int_{\Omega} \nabla_{\mathrm{v}} \cdot \nabla \mathrm{v}_{\mathrm{h}} \mathrm{dx}
$$

We use the inequality of Holder, then we get:

$$
\left\|\nabla \mathrm{R}_{\mathrm{h}} \mathrm{v}\right\|_{0}^{2}, \Omega \leq\left\|\nabla \mathrm{R}_{\mathrm{h}} \mathrm{v}\right\| 0, \Omega\left\|\nabla_{\mathrm{v}}\right\| 0, \Omega
$$

We conclude that:

$$
\left\|\nabla \mathrm{R}_{\mathrm{h}} \mathrm{v}\right\| 0, \Omega \leq\left\|\nabla_{\mathrm{v}}\right\| 0, \Omega
$$

We find that $R_{h}$ is continuous in the sense of $\mathrm{H}_{0}^{1}(\Omega) \cap \mathrm{V}$ and by the density of $\mathrm{H}_{0}^{1}(\Omega)$ in $\mathrm{H}^{1}(\Omega)$, it means that $\overline{\mathrm{H}_{0}^{1}(\Omega) \cap \mathrm{V}^{111, \Omega}} \subset \mathrm{H}^{1}(\Omega)$, so, we have its continuity in the space $V$ then, we suppose that the operator $R_{h}$ checks the next properties of estimation that is to say, there exist $c>0$ independent of $h$ and $v$ :

$$
\left\|\left(\mathrm{R}_{\mathrm{h}} \mathrm{v}-\mathrm{v}\right)\right\| 0, \Omega \leq \mathrm{ch}\left\|\nabla_{\nabla}\right\| 0, \Omega
$$

The above findings are workable for all $\mathrm{v} \in \mathrm{V}$. Now, let prove that the relation (Eq. 35) in lemma (2), just show:

$$
\int_{\Omega h} \nabla \cdot u_{h} q_{h} d x=\int_{\Omega h} \nabla \cdot u q_{h} d x \forall K \in T_{h}
$$

By applying the Green equation, we find that (Eq. 42) is equivalent to:

$$
\int_{\Omega_{\mathrm{h}}} \nabla \mathrm{q}_{\mathrm{h}} \cdot \mathrm{u}_{\mathrm{h}} \mathrm{dx}=\int_{\Omega_{\mathrm{h}}} \nabla \mathrm{q}_{\mathrm{h}} \nabla \mathrm{q}_{\mathrm{h}} \cdot \mathrm{udx}
$$

But $\nabla \mathrm{q}_{\mathrm{h}}$ is constant when $\mathrm{q}_{\mathrm{h}} \in \mathrm{P}_{1}(\mathrm{~K})$. So, just prove that there exist $u_{h} \in V_{h}$ :

$$
\int_{K} u_{h} d x=\int_{K} u d x \forall K \in T_{h}
$$

Indeed, by the definition of the space $V_{h}$ for every function $\mathrm{u}_{\mathrm{h}}$ of $\mathrm{V}_{\mathrm{h}}$ is determined by the relation:

$$
\mathrm{u}_{\mathrm{h}}=\sum_{\mathrm{i}=1}^{3} \mathrm{u}_{\mathrm{h}}\left(\mathrm{a}_{\mathrm{i}}^{\mathrm{K}}\right) \lambda_{\mathrm{i}}(\mathrm{x})+\beta^{\mathrm{K}} \mu^{\mathrm{k}}(\mathrm{x}) \forall \mathrm{x} \in \mathrm{K}
$$

We go to the integral on $\mathrm{K}$, we have:

$$
\begin{array}{r}
\int_{\mathrm{K}} \mathrm{u}_{\mathrm{h}} \mathrm{dx}=\sum_{\mathrm{i}=1}^{3} \mathrm{u}_{\mathrm{h}}\left(\mathrm{a}_{\mathrm{i}}^{\mathrm{K}}\right) \int_{\mathrm{k}} \lambda_{\mathrm{i}}(\mathrm{x}) \mathrm{dx}+\beta^{\mathrm{K}} \int_{\mathrm{K}} \mu^{\mathrm{K}}(\mathrm{x}) \mathrm{dx} \\
=\sum_{\mathrm{i}=1}^{3} \mathrm{R}_{\mathrm{h}} \mathrm{u}\left(\mathrm{a}_{\mathrm{i}}^{\mathrm{K}}\right) \int_{\mathrm{K}} \lambda_{\mathrm{i}}(\mathrm{x}) \mathrm{dx}+\beta^{\mathrm{K}} \int_{\mathrm{K}} \mu^{\mathrm{K}}(\mathrm{x}) \mathrm{dx} \\
=\int_{\mathrm{K}} \mathrm{R}_{\mathrm{h}} \mathrm{udx}=\int_{\mathrm{K}} \mathrm{udx}
\end{array}
$$

We have chosen $u_{h} \in V_{h}$ such as $u_{h}\left(a_{i}=R_{h} u\left(a_{i}\right)\right.$ for all $\mathrm{a}_{1}{ }^{\mathrm{K}}$ top of $\mathrm{K}$ who verifies (Eq. 35) of lemma (2). Now let, prove the relation (Eq. 36) of lemma (2) we have:

$$
\left.\mathrm{u}_{\mathrm{h}}\right|_{\mathrm{K}}=\sum_{\mathrm{i}=1}^{3} \mathrm{R}_{\mathrm{h}} \mathrm{u}\left(\mathrm{a}_{\mathrm{i}}^{\mathrm{K}}\right) \lambda_{\mathrm{i}}+\beta^{\mathrm{K}} \mu^{\mathrm{K}}
$$

With a simple writing $\left.u_{h}\right|_{K}=R_{h, u}+\beta^{K} \mu^{K}$ and $\left\|\mathbf{u}_{\mathrm{h}}\right\|_{1}^{2}, \Omega=\sum \mathrm{K} \in \mathrm{T}_{\mathrm{h}}\|\mathbf{u} \mathbf{h}\|_{1, \mathrm{~K}}^{2}$ then: 


$$
\begin{aligned}
\left\|\mathrm{u}_{\mathrm{h}}\right\|_{1}^{2}, \Omega \leq & \sum_{\mathrm{K} \in \mathrm{T}_{\mathrm{h}}}\left(\left\|\mathrm{R}_{\mathrm{h}} \mathrm{u}\right\| 1, \mathrm{~K}+\left|\beta^{\mathrm{K}}\right|\left\|\mu^{\mathrm{K}}\right\| 1, \mathrm{~K}\right)^{2} \\
& \leq 2 \sum_{\mathrm{K} \in \mathbb{T}_{\mathrm{h}}}\left(\left\|\mathrm{R}_{\mathrm{h}} \mathrm{u}\right\|_{1}^{2}, \mathrm{~K}+\left|\beta^{\mathrm{K}}\right|^{2}\left\|\mu^{\mathrm{K}}\right\|_{1, \mathrm{~K}}^{2}\right) \\
& \leq 2\left\|\mathrm{R}_{\mathrm{h}} \mathrm{u}\right\|_{1}^{2}, \Omega+2 \sum_{\mathrm{K} \in T_{\mathrm{h}}}\left|\beta^{\mathrm{K}}\right|^{2}\left\|\mu^{\mathrm{K}}\right\|_{1, \mathrm{~K}}^{2}
\end{aligned}
$$

By the continuity of the operator $\mathrm{R}_{\mathrm{h}}$ :

$$
\left\|\mathrm{u}_{\mathrm{h}}\right\|_{1}^{2}, \Omega \leq \mathrm{c}\|\mathrm{u}\|_{1}^{2}, \Omega+2 \sum_{\mathrm{K} \in \mathrm{T}_{\mathrm{h}}}\left|\beta^{\mathrm{K}}\right|^{2}\left\|\mu^{\mathrm{K}}\right\|_{1, \mathrm{~K}}^{2}
$$

By using the relation (Eq. 35) of lemma (2) and $\int_{K} u_{h} d x=\int_{K} R_{h} u d x+\beta^{K} \int_{K} \mu^{K} d x$ we find that:

$$
\beta^{\mathrm{K}}=\frac{\int_{\mathrm{K}}\left(\mathrm{u}-\mathrm{R}_{\mathrm{h}} \mathrm{u}\right) \mathrm{dx}}{\int_{\mathrm{K}} \mu^{\mathrm{K}} \mathrm{dx}}
$$

Using Cauchy-Schwarz, it gives the existence of $\mathrm{c}_{0}>0$ independent of $\mathrm{h}$ and $\mathrm{K}$, so as:

$$
\left|\beta^{\mathrm{K}}\right|^{2} \leq \mathrm{c}_{0} \frac{\left\|\mathrm{u}-\mathrm{R}_{\mathrm{h}} \mathrm{u}\right\|_{0, \mathrm{~K}}^{2}}{\mathrm{~h}^{2}}
$$

The function $\mu^{\mathrm{K}}$ is bounded in the sense of the norm $\|\| 1,, \mathrm{~K}$ and by the relation (Eq. 41) we get the relation (Eq. 36) of lemma (Eq. 2). Finally, it was also shown that the mini-element P1-bubble/P1 satisfies the condition inf-sup discreet.

Theorem 3: There exist strictly positive constant $\xi$ for all $\mathrm{u}_{\mathrm{h}} \in \mathrm{V}_{\mathrm{h}}$ we have the:

$$
\mathrm{a}\left(\mathrm{u}_{\mathrm{h}}, \mathrm{u}_{\mathrm{h}}\right) \geq \xi\left\|\mathrm{u}_{\mathrm{h}}\right\|_{1, \mathrm{~s}}^{2}
$$

The (Eq. 52) indicates that the bilinear form a is coercive on the space $V_{h}$.

Proof: we define the bilinear form $\mathrm{a}_{0}$ on $\mathrm{V}_{\mathrm{h}}$ :

$$
\mathrm{a}_{0}\left(\mathrm{u}_{\mathrm{h}}, \mathrm{v}_{\mathrm{h}}\right)=\int_{\Omega} \mu \nabla \mathrm{h}: \nabla \mathrm{v}_{\mathrm{h}} \mathrm{d} \Omega
$$

With (Eq. 53), the bilinear form can a be written in the form $\mathrm{a}\left(\mathrm{u}_{\mathrm{h}}, \mathrm{v}_{\mathrm{h}}\right)=\mathrm{a}_{0}\left(\mathrm{u}_{\mathrm{h}}, \mathrm{v}_{\mathrm{h}}\right)+\int_{\Gamma} \mathrm{B}^{-1} \mathrm{Au}_{\mathrm{h}} \mathrm{V}_{\mathrm{h}} \mathrm{d} \Gamma$. To show that $\mathrm{a}_{0}$ verifies this property, it suffices to show that it is definite positive, since, the space $V_{h}$ is of finite dimension.

If $\mathrm{a}\left(\mathrm{u}_{\mathrm{h}}, \mathrm{v}_{\mathrm{h}}\right)$ is zero, then $\mathrm{u}_{\mathrm{h}}$ is constant on each triangle. Since, there is continuity in the middle of each edge, then $u_{h}$ is globally constant. As it vanisheson the midst of the edge contained in the boundary of $\Omega$. So, $u_{h}$ is identically zero. Then we can write:

$$
\mathrm{a}_{0}\left(\mathrm{u}_{\mathrm{h}}, \mathrm{u}_{\mathrm{h}}\right) \geq \xi_{0}\left\|\mathrm{u}_{\mathrm{h}}\right\|_{1}^{2}, \Omega
$$

By using (Eq. 9), it is easy to show that there exist a strictly positive constants $v$ and for all $\mathrm{u}_{\mathrm{h}} \in \mathrm{V}_{\mathrm{h}}$ we have:

$$
\int_{\Gamma}\left|\mathrm{B}^{-1} \mathrm{Au}_{\mathrm{h}} \cdot \mathrm{u}_{\mathrm{h}}\right| \mathrm{d} \Gamma \leq \mathrm{v}\left\|\mathrm{u}_{\mathrm{h}}\right\|_{1, \Omega}^{2}
$$

If $\mathrm{B}^{-1} \mathrm{Au}_{\mathrm{h}} \cdot \mathrm{u}_{\mathrm{h}}<0$ with (Eq. 54 and 55), we obtain:

$$
\mathrm{a}\left(\mathrm{u}_{\mathrm{h}}, \mathrm{u}_{\mathrm{h}}\right) \geq\left(\xi_{0}-\mathrm{v}\right)\left\|\mathrm{u}_{\mathrm{h}}\right\|_{\mathrm{h}, \mathrm{s}}^{2}
$$

Since, $\xi_{0}-v>0$ If not, $\mathrm{B}^{-1} \mathrm{Au}_{\mathrm{h}} \cdot \mathrm{u}_{\mathrm{h}}>0$, we have:

$$
a\left(u_{h}, u_{h}\right) \geq a_{0}\left(u_{h}, u_{h}\right) \geq \xi_{0}\left\|u_{h}\right\|_{1, ~}^{2}
$$

Finally, we combine (Eq. 57 and 56) we result that $\mathrm{a}\left(\mathrm{u}_{\mathrm{h}}, \mathrm{u}_{\mathrm{h}}\right) \geq\left(\xi_{0}-v\right)\left\|\mathrm{u}_{\mathrm{h}}\right\|_{1,}^{2}$, for all $\mathrm{u}_{\mathrm{h}} \in \mathrm{V}_{\mathrm{h}}$, since, $\xi_{0}-\mathrm{v}>0$.

Algebric problem: In this study, we introduce the matrices $A, B_{T}, B, D$ L related to the descret bilinear forms $a_{h}, b_{T h}, b_{h}, d_{h}, L_{h}$, respectively in the following way and we can express the bilinear forms according to the operations as well defined here:

$$
\left\{\begin{aligned}
& a_{h}\left(u_{h}, v_{h}\right)=(\left(u_{h}, v_{h}\right) \\
& b_{\Gamma h}\left(v_{h}, q_{h}\right)=(\left(B_{\Gamma} v_{h}, q_{h}\right) \\
& b_{h}\left(u_{h}, q_{h}\right)=\left(B v_{h}, q_{h}\right) \forall q_{h} \\
& d_{h}\left(\psi_{h}, q_{h}\right)=\left(D \psi_{h}, q_{h}\right) \\
& L_{h}\left(v_{h}\right)=L v_{h}
\end{aligned}\right.
$$

for all $\left(\mathrm{u}_{\mathrm{h}}, \mathrm{v}_{\mathrm{h}}\right) \in \mathrm{V}_{\mathrm{h}}(\Omega) \times \mathrm{V}_{\mathrm{h}}(\Omega)$ and $\left(\psi_{\mathrm{h}}, \mathrm{q}_{\mathrm{h}}\right) \in \mathrm{M}_{\mathrm{h}}(\Omega) \times \mathrm{M}_{\mathrm{h}}(\Omega)$. With (Eq. 58), we find that the discrete formulation (Eq. 20) can be expressed as a system of operator Eq. 59:

$$
\left\{\begin{array}{l}
\mathrm{A}_{u_{\mathrm{h}}}+\mathrm{B}_{\Gamma}^{\mathrm{t}} \Psi=\mathrm{L} \\
\mathrm{B}_{u_{\mathrm{h}}}-\mathrm{D} \Psi_{\mathrm{h}}=0
\end{array}\right.
$$

We find that the discrete formulation can be expressed as a system of linear equations as well:

$$
\left(\begin{array}{cc}
\mathrm{A} & \mathrm{B}_{\Gamma}^{\mathrm{t}} \\
\mathrm{B} & -\mathrm{D}
\end{array}\right)\left(\begin{array}{l}
\mathrm{u}_{\mathrm{h}} \\
\psi_{\mathrm{h}}
\end{array}\right)=\left(\begin{array}{c}
\mathrm{L} \\
0
\end{array}\right)
$$

With $u_{h}=\left(u_{x}, u_{y}\right)^{t}$, we can express the algebric system (Eq. 59) as follows:

$$
\left(\begin{array}{ccc}
A_{x} & 0 & B_{\Gamma, x}^{t} \\
0 & A_{y} & B_{\Gamma, y}^{t} \\
B_{z} & B_{y} & -D
\end{array}\right)\left(\begin{array}{c}
u_{z} \\
u_{y} \\
\psi
\end{array}\right)=\left(\begin{array}{c}
L_{z} \\
L_{y} \\
0
\end{array}\right)
$$


Let $\left\{\varphi_{1}, \varphi_{2}, \varphi_{3}\right\}$ be the finite element basis formed of scalar functions $\varphi_{\mathrm{i}}, \mathrm{I}=1, \ldots, \mathrm{n}$. In practice the two components of $\left(\mathrm{u}_{\mathrm{h}}^{\mathrm{x}} \mathrm{u}_{\mathrm{h}}^{\mathrm{y}}\right)$ of $\mathrm{u}_{\mathrm{h}}$ are always appreciated by one space finite element. Let $\mathrm{N}$ be the number of nodes in the finite element mesh and $n=N-n_{s}$ with $n s$ the number of vertices on the boundries. The basis of the space $V_{h}$ :

$$
\mathrm{BV}_{\mathrm{h}}=\left\{\begin{array}{l}
\phi_{1}=\left(\varphi_{1}, 0\right), \ldots, \phi_{\mathrm{n}}=\left(\varphi_{\mathrm{n}}, 0\right) \\
\phi_{\mathrm{n}+1}=\left(0, \varphi_{1}\right), \ldots, \phi_{2 \mathrm{n}}=\left(0, \varphi_{\mathrm{n}}\right)
\end{array}\right\}
$$

Then $u_{h}=\left(u_{h}^{x} u_{h}^{y}\right) \varepsilon V_{h}$ can be gives by the relation:

$$
\mathrm{u}_{\mathrm{h}}=\mathrm{u}_{1}^{\mathrm{x}} \phi_{1}+, \ldots,+\mathrm{u}_{\mathrm{n}}^{\mathrm{x}} \phi_{\mathrm{n}}+\mathrm{u}_{1}^{\mathrm{y}} \phi_{\mathrm{n}}+1+, \ldots,+\mathrm{u}_{\mathrm{n}}^{\mathrm{y}} \phi_{2 \mathrm{n}}
$$

For a given triangle $\mathrm{K}$, the displacement field $\mathrm{u}_{\mathrm{h}}$ and the divergence $\psi_{\mathrm{h}}$ are approximated by linear combinations of the basis functions in the form:

$$
\begin{aligned}
& u_{h}^{x}=\sum_{i=1}^{3} u_{i}^{x} \varphi_{i}+u_{b} \varphi_{b} \\
& u_{h}^{y}=\sum_{i=1}^{3} u_{i}^{y} \varphi_{i}+u_{b} \varphi_{b} \\
& \psi_{h}=\sum_{i=1}^{3} \psi_{i} \varphi_{i}
\end{aligned}
$$

The linear system (Eq. 61), attached to the discrete system (Eq. 59) is evaluated over each triangle $\mathrm{K}$ to obtain the element of the local matrices and the global matrices are denoted by uppercase letters and are given by direct summing. Assuming that $\left(\mathrm{B}^{-1} \mathrm{~A}\right)_{i \mathrm{ij}}=\alpha_{\mathrm{ij}}$ and $\left(\mathrm{B}^{-1}\right)_{\mathrm{ij}}=\beta_{\mathrm{ij}}$ for $\mathrm{i}$, $\mathrm{j}=1,2$. The matrices elements over the domain $\Omega$ are given by:

$$
\begin{array}{r}
\mathrm{a}_{\mathrm{ij}}^{0}=\int_{\mathrm{K}} \mu \nabla \varphi_{\mathrm{i}} \nabla \varphi_{\mathrm{j}} \mathrm{dK} \\
\mathrm{a}_{0}=\sum_{\mathrm{K} \in \mathrm{T}_{\mathrm{h}}} \mathrm{a}_{1 j}^{0} \\
\mathrm{a}_{\mathrm{ij}}^{\mathrm{x}}=\mathrm{a}_{\mathrm{ij}}^{0}+\int_{\mathrm{E} \cap K \subset \Gamma_{\mathrm{h}}} \alpha_{11} \varphi_{\mathrm{i}} \varphi_{\mathrm{j}} \mathrm{d} \Gamma_{\mathrm{h}} \\
\mathrm{A}_{\mathrm{z}}=\sum_{\mathrm{K} \in T_{\mathrm{h}}} \mathrm{a}_{\mathrm{ij}}^{\mathrm{x}} \\
\mathrm{a}_{\mathrm{ij}}^{\mathrm{y}}=\mathrm{a}_{\mathrm{ij}}^{0}+\int_{E \cap K \subset \Gamma_{\mathrm{h}}} \alpha_{22} \varphi_{\mathrm{i}} \varphi_{\mathrm{j}} \mathrm{d} \Gamma_{\mathrm{h}} \\
\mathrm{A}_{\mathrm{y}}=\sum_{\mathrm{K} \in \mathrm{T}_{\mathrm{h}}} \mathrm{a}_{\mathrm{ij}}^{\mathrm{y}} \\
\mathrm{b}_{\mathrm{ij}}^{\mathrm{x}}=\int_{\mathrm{K}}(\lambda+\mu) \frac{\partial \varphi_{\mathrm{i}}}{\partial_{\mathrm{y}}} \varphi_{\mathrm{j}} \mathrm{dK} \\
\mathrm{B}^{\mathrm{z}}=\sum_{\mathrm{K} \in T_{\mathrm{h}}} \mathrm{b}_{\mathrm{ij}}^{\mathrm{x}}
\end{array}
$$

$$
\begin{aligned}
& b_{i j}^{y}=\int_{K}(\lambda+\mu) \frac{\partial \varphi_{i}}{\partial_{y}} \varphi_{j} \mathrm{dK} \\
& \mathrm{B}_{\mathrm{y}}=\sum_{\mathrm{K} \in \mathrm{T}_{\mathrm{h}}} \mathrm{b}_{\mathrm{ij}}^{\mathrm{y}} \\
& b_{\Gamma j}^{\mathrm{x}}=b_{\mathrm{ij}}^{\mathrm{x}}+\int_{E \cap K \subset \Gamma_{\mathrm{h}}} \mu \varphi_{\mathrm{i}} \mathrm{n}_{\mathrm{ij}} \varphi_{\mathrm{j}} \mathrm{dE} \\
& \mathrm{B}_{\Gamma}^{\mathrm{x}}=\sum_{\mathrm{K} \in T_{\mathrm{h}}} \mathrm{b}_{\Gamma_{\mathrm{ij}}}^{\mathrm{x}} \\
& b_{\Gamma_{i j}}^{y}=b_{i j}^{y}+\int_{E \cap K \subset \Gamma_{h}} \mu \varphi_{i} n_{i j} \varphi_{j} d E \\
& \mathrm{~B}_{\Gamma}^{\mathrm{y}}=\sum_{\mathrm{K} \in T_{\mathrm{T}}} \mathrm{b}_{\Gamma_{\mathrm{ij}}}^{\mathrm{y}} \\
& \mathrm{d}_{\mathrm{ij}}=\int_{\mathrm{K}}(\lambda+\mu) \varphi_{\mathrm{i}} \varphi_{\mathrm{j}} \mathrm{dK} \\
& \mathrm{D}=\sum_{\mathrm{K} \in \mathrm{T}_{\mathrm{h}}} \mathrm{d}_{\mathrm{ij}} \\
& \mathrm{I}_{\mathrm{i}}^{0 \mathrm{x}}=\int_{\mathrm{K}} \mathrm{f}_{1} \varphi_{\mathrm{i}} \mathrm{dK} \\
& 1_{\mathrm{i}}^{\mathrm{z}}=1_{\mathrm{i}}^{0 \mathrm{x}}+\int_{\mathrm{E} \cap \mathrm{K} \subset \Gamma_{\mathrm{h}}}\left(\beta_{11}+\beta_{21}\right) \mathrm{g}_{1} \varphi_{\mathrm{i}} \mathrm{dE} \\
& \mathrm{L}^{\mathrm{z}}=\sum_{\mathrm{K} \in \mathrm{T}_{\mathrm{h}}} 1_{\mathrm{i}}^{\mathrm{x}} \\
& 1_{i}^{0 y}=\int_{\mathrm{K}} \mathrm{f}_{2} \varphi_{\mathrm{i}} \mathrm{dK} \\
& 1_{\mathrm{i}}^{\mathrm{y}}=1_{\mathrm{i}}^{0 \mathrm{y}}+\int_{\mathrm{E} \cap \mathrm{K} \subset \Gamma_{\Gamma \mathrm{h}}}\left(\beta_{12}+\beta_{22}\right) \mathrm{g}_{2} \varphi_{\mathrm{i}} \\
& L^{y}=\sum_{K \in T_{h}} 1_{1}^{y} d E
\end{aligned}
$$

Knowing that $\mathrm{f}=\left(\mathrm{f}_{1}, \mathrm{f}_{2}\right)^{\mathrm{t}}, \mathrm{g}=\left(\mathrm{g}_{1}, \mathrm{~g}_{2}\right)^{\mathrm{t}} \mathrm{n}_{\mathrm{ij}}=0,1$ or- 1

Element matrices: In this paragraph, we calculate elementary matrices in Eq. 65-74 in order to carry them out. The calcula tions which have already been made in the study (Koko, 2012) will be based. For a traingle K let $\left(x_{i} ; y_{i}\right)_{i=1,2,3}$ be the vertices and the basis functions are defined by:

$$
\begin{aligned}
& \varphi_{1}(\mathrm{x}, \mathrm{y})=1-\mathrm{x}-\mathrm{y}, \varphi_{2}(\mathrm{x}, \mathrm{y})=\mathrm{x} \\
& \varphi_{3}(\mathrm{x}, \mathrm{y})=\mathrm{y}, \varphi_{\mathrm{b}}=27 \varphi_{1} \varphi_{2} \varphi_{3}
\end{aligned}
$$

We need the following notations:

$$
\mathrm{x}_{\mathrm{ij}}=\mathrm{x}_{\mathrm{i}}-\mathrm{x}_{\mathrm{j}}, \mathrm{y}_{\mathrm{ij}}=\mathrm{y}_{\mathrm{i}}-\mathrm{y}_{\mathrm{j}} \mathrm{i}, \mathrm{j}=1,2,3
$$


And:

$$
\begin{aligned}
& \mathrm{x}^{(\mathrm{K})}=\left(\begin{array}{l}
\mathrm{x}_{32} \\
\mathrm{x}_{13} \\
\mathrm{x}_{21}
\end{array}\right)=\left(\begin{array}{l}
\mathrm{x}_{1}{ }^{(\mathrm{K})} \\
\mathrm{x}_{2}{ }^{(\mathrm{K})} \\
\mathrm{x}_{3}{ }^{(\mathrm{K})}
\end{array}\right) \\
& \mathrm{y}^{(\mathrm{K})}=\left(\begin{array}{l}
\mathrm{y}_{32} \\
\mathrm{y}_{13} \\
\mathrm{y}_{21}
\end{array}\right)=\left(\begin{array}{l}
\mathrm{y}_{1}{ }^{(\mathrm{K})} \\
\mathrm{y}_{2}{ }^{(\mathrm{K})} \\
\mathrm{y}_{3}{ }^{(\mathrm{K})}
\end{array}\right)
\end{aligned}
$$

The nonbubble part of the matrix $\mathrm{A}$ is writeen like:

$$
A_{0}^{K}=\left(a_{i j}^{0}\right) i, j=1,2,3=\frac{\mu}{4|K|}\left(y^{(K)} y^{(K) t}+x^{(K)} x^{(K) t}\right)
$$

With $|\mathrm{K}|=\frac{\mathrm{x}_{3}{ }^{(\mathrm{K})} \mathrm{y}_{1}{ }^{(\mathrm{K})}-\mathrm{x}_{2}{ }^{(\mathrm{K})} \mathrm{y}_{3}{ }^{(\mathrm{K})}}{2}$ The bubble part of $\mathrm{A}_{0}$ are $\mathrm{A}_{\mathrm{b}}=$

$\left(a_{b j}\right)_{j=1,2,3}=0_{31}$ with $0_{31}$ is a zero coulmn vector with 3 elements and for the diagonal:

$$
\begin{aligned}
& \mathrm{a}_{\mathrm{bb}}=\frac{81 \mu}{10}|\mathrm{~K}|\left(\left|\nabla \varphi_{1}\right|^{2}\right.\left.+\left|\nabla \varphi_{2}\right|^{2}+\nabla \varphi_{1} \cdot \nabla \varphi_{2}\right) \\
&=\frac{81 \mu}{40} \frac{1}{|\mathrm{~K}|}\left(\left(\mathrm{x}_{1}{ }^{(\mathrm{K})}\right)^{2}+\left(\mathrm{x}_{2}{ }^{(\mathrm{K})}\right)^{2}+\left(\mathrm{y}_{1}{ }^{(\mathrm{K})}\right)^{2}\right. \\
&\left.+\left(\mathrm{y}_{2}{ }^{(\mathrm{K})}\right)^{2}+\mathrm{x}_{1}{ }^{(\mathrm{K})} \mathrm{x}_{2}{ }^{(\mathrm{K})}+\mathrm{y}_{1}{ }^{(\mathrm{K})} \mathrm{y}_{2}{ }^{(\mathrm{K})}\right)
\end{aligned}
$$

Since, the stiffness matrix $\mathrm{A}_{0}$ is symmetric then, we have:

$$
A_{0}=\left(\begin{array}{cc}
A_{0}^{K} & A^{b} \\
A_{b}^{t} & a_{b b}
\end{array}\right)=\left(\begin{array}{cc}
A_{0}^{K} & 0 \\
0 & a_{b b}
\end{array}\right)
$$

The the mass matrix $D$ is given by for $i, j=1,2,3$ :

$$
D=\left\{\begin{array}{l}
\frac{\mu+\lambda}{6}|\mathrm{~K}|, \mathrm{i}=\mathrm{j} \\
\frac{\mu+\lambda}{12}|\mathrm{~K}| \mathrm{i} \neq \mathrm{j}
\end{array}\right.
$$

Now, we will implement the divergence matrices, the element matrices of nonbubble part of $\mathrm{B}_{\mathrm{x}}$ and $\mathrm{B}_{\mathrm{y}}$ are given by:

$$
B_{x}^{K}=\frac{1}{6}(\mu+\lambda)\left(\begin{array}{l}
y^{(K) t} \\
y^{(K) t} \\
y^{(K) t}
\end{array}\right)
$$

$$
B_{y}^{K}=\frac{1}{6}(\mu+\lambda)\left(\begin{array}{l}
x^{(K) t} \\
x^{(K) t} \\
x^{(K) t}
\end{array}\right)
$$

The bubble part are given like:

$$
\mathrm{B}_{\mathrm{xb}}=(\mu+\lambda) \frac{9}{40} \mathrm{y}^{(\mathrm{K}) \mathrm{t}}, \mathrm{B}_{\mathrm{yb}}=(\mu+\lambda) \frac{9}{40} \mathrm{x}^{(\mathrm{K}) \mathrm{t}}
$$

Finally, we find that:

$$
\mathrm{B}_{\mathrm{z}}=\left(\begin{array}{c}
\mathrm{B}_{\mathrm{x}}^{\mathrm{K}} \\
\mathrm{B}_{\mathrm{zb}}
\end{array}\right), \mathrm{B}_{\mathrm{y}}=\left(\begin{array}{c}
\mathrm{B}_{\mathrm{y}}^{\mathrm{K}} \\
\mathrm{B}_{\mathrm{yb}}
\end{array}\right)
$$

Element right-hand side: The nonbubble part of the external forces is given by:

$$
1_{\mathrm{K}}^{0 \mathrm{x}}=\frac{|\mathrm{K}|}{3} \mathrm{f}_{1 \mathrm{~K}}\left(\begin{array}{l}
1 \\
1 \\
1
\end{array}\right), \mathrm{I}_{\mathrm{K}}^{0 \mathrm{y}}=\frac{|\mathrm{K}|}{3} \mathrm{f}_{2 \mathrm{~K}}\left(\begin{array}{l}
1 \\
1 \\
1
\end{array}\right)
$$

where:

$$
\mathrm{f}_{\mathrm{iK}}=\frac{\left(\mathrm{f}_{\mathrm{i}}\left(\mathrm{x}_{1}\right)+\mathrm{f}_{\mathrm{i}}\left(\mathrm{x}_{2}\right)+\mathrm{f}_{\mathrm{i}}\left(\mathrm{x}_{3}\right)\right)}{3}, \mathrm{i}=1,2
$$

The bubble part of the right-hand side are:

$$
1_{\mathrm{xb}}=\frac{9}{20}|\mathrm{~K}| \mathrm{f}_{1 \mathrm{~K}}, 1_{\mathrm{yb}}=\frac{9}{20}|\mathrm{~K}| \mathrm{f}_{2 \mathrm{~K}}
$$

Finally, we have:

$$
1_{0 \mathrm{x}}=\left(\begin{array}{c}
1_{\mathrm{K}}^{0 \mathrm{x}} \\
1 \mathrm{xb}
\end{array}\right), 1_{\mathrm{y}}=\left(\begin{array}{c}
1_{\mathrm{K}}^{0 \mathrm{y}} \\
1_{\mathrm{yb}}
\end{array}\right)
$$

Now, we will build the matrix of $11 \times 11$ corresponding to the system:

$$
\left(\begin{array}{ccccc}
\mathrm{A}_{\mathrm{z}}^{\mathrm{k}} & 0 & 0 & 0 & \mathrm{~B}_{\Gamma, \mathrm{z}}^{\mathrm{t}} \\
0 & \mathrm{a}_{\mathrm{bb}} & 0 & 0 & \mathrm{~B}_{\mathrm{b} \Gamma, \mathrm{z}}^{\mathrm{t}} \\
0 & 0 & \mathrm{~A}_{\mathrm{y}}^{\mathrm{K}} & 0 & \mathrm{~B}_{\Gamma, y}^{\mathrm{t}} \\
0 & 0 & 0 & \mathrm{a}_{\mathrm{bb}} & \mathrm{B}_{\mathrm{b} \Gamma, \mathrm{y}}^{\mathrm{t}} \\
\mathrm{B}_{\mathrm{z}}^{\mathrm{K}} & \mathrm{B}_{\mathrm{bz}} & \mathrm{B}_{\mathrm{y}}^{\mathrm{K}} & \mathrm{B}_{\mathrm{by}} & -\mathrm{D}
\end{array}\right)\left(\begin{array}{c}
\mathrm{u}_{\mathrm{z}} \\
\mathrm{u}_{\mathrm{bz}} \\
\mathrm{u}_{\mathrm{y}} \\
\mathrm{u}_{\mathrm{by}} \\
\Psi
\end{array}\right)=\left(\begin{array}{c}
1_{\mathrm{K}}^{\mathrm{z}} \\
1_{\mathrm{bx}} \\
1_{\mathrm{K}}^{\mathrm{z}} \\
1_{\mathrm{by}} \\
0
\end{array}\right)
$$

We will classify the system Eq. 92 in such a way that we can describe the bubble part of the unknown $u$ as a function of the nonbubble part of $u$ and $\psi$ in order to be able to eliminate it thereafter: 


$$
\left(\begin{array}{ccccc}
\mathrm{A}_{\mathrm{z}}^{\mathrm{k}} & 0 & 0 & 0 & \mathrm{~B}_{\Gamma, \mathrm{z}}^{\mathrm{t}} \\
0 & \mathrm{~A}_{\mathrm{y}}^{\mathrm{k}} & 0 & 0 & \mathrm{~B}_{\Gamma, y}^{\mathrm{t}} \\
0 & 0 & \mathrm{a}_{\mathrm{bb}} & 0 & \mathrm{~B}_{\mathrm{b} \Gamma, \mathrm{z}}^{\mathrm{t}} \\
0 & 0 & 0 & \mathrm{a}_{\mathrm{bb}} & \mathrm{B}_{\mathrm{b \Gamma ,y}}^{\mathrm{t}} \\
\mathrm{B}_{\mathrm{x}}^{\mathrm{K}} & \mathrm{B}_{\mathrm{y}}^{\mathrm{K}} & \mathrm{B}_{\mathrm{bz}} & \mathrm{B}_{\mathrm{by}} & -\mathrm{D}
\end{array}\right)\left(\begin{array}{c}
\mathrm{u}_{\mathrm{z}} \\
\mathrm{u}_{\mathrm{y}} \\
\mathrm{u}_{\mathrm{bx}} \\
\mathrm{u}_{\mathrm{by}} \\
\Psi
\end{array}\right)=\left(\begin{array}{c}
\mathrm{1}_{\mathrm{z}}^{\mathrm{K}} \\
1_{\mathrm{y}}^{\mathrm{K}} \\
1_{\mathrm{bz}} \\
1_{b y} \\
0
\end{array}\right)
$$

From line 3 and 4 of the system (Eq. 93), we duduces:

$$
\begin{aligned}
& \mathrm{u}_{\mathrm{bx}}=\mathrm{a}_{\mathrm{bb}}^{-1}\left(1_{\mathrm{bx}}-\mathrm{B}_{\mathrm{b} \Gamma, \mathrm{z}}^{\mathrm{t}} \Psi\right) \\
& \mathrm{u}_{\mathrm{by}}=\mathrm{a}_{\mathrm{bb}}^{-1}\left(1_{\mathrm{by}}-\mathrm{B}_{\mathrm{b} \Gamma, \mathrm{y}}^{\mathrm{t}} \Psi\right)
\end{aligned}
$$

With the elimination of $u_{b x}$ and $u_{b y}$, we find the new linear system with the matrics in:

$$
\begin{gathered}
\mathbb{U}=\left(\begin{array}{c}
\mathrm{u}_{\mathrm{z}} \\
\mathrm{u}_{\mathrm{y}} \\
\psi
\end{array}\right) \\
\mathbb{A}=\left(\begin{array}{ccc}
\mathrm{A}_{\mathrm{X}}^{\mathrm{K}} & 0 & \mathrm{~B}_{\Gamma, \mathrm{z}}^{\mathrm{t}} \\
0 & \mathrm{~A}_{\mathrm{Y}}^{\mathrm{K}} & \mathrm{B}_{\Gamma}^{\mathrm{t}}, \mathrm{y} \\
\mathrm{B}_{\mathrm{X}}^{\mathrm{K}} & \mathrm{B}_{\mathrm{Y}}^{\mathrm{K}} & -\mathrm{B}_{\mathrm{bx}} 1 \mathrm{~B}_{\mathrm{b \Gamma}, \mathrm{x}}^{\mathrm{t}} \mathrm{a}_{\mathrm{bb}}^{-1}-\mathrm{B}_{\mathrm{by}} \mathrm{B}_{\mathrm{b \Gamma}, \mathrm{y}}^{\mathrm{t}} \mathrm{a}_{\mathrm{bb}}^{-1}-\mathrm{D}
\end{array}\right)
\end{gathered}
$$

And the right hand:

$$
\mathbb{F}=\left(\begin{array}{c}
1_{\mathrm{x}}^{\mathrm{K}} \\
1_{\mathrm{y}}^{\mathrm{K}} \\
-\mathrm{B}_{\mathrm{bx}} 1_{\mathrm{bx}} \mathrm{a}_{\mathrm{bb}}^{-1}-\mathrm{B}_{\mathrm{by}} 1_{\mathrm{by}} \mathrm{a}_{\mathrm{bb}}^{-1}
\end{array}\right)
$$

\section{RESULTS AND DISCUSSION}

This study is the fruit of the study that is done in the previous sections in this stduy with its two sides: Mathematics and programming. So, there is some numerical results of calculations with mixed finite element P1 bublle-P1 method and the ordinary finite element method that is done in the study. A two-dimensional problem with the elastic square body with a hole schematically by Fig. 1 and $2 \Omega=[0,2] \times[0,2] / \mathrm{B}(0,1)$.

$(\mathrm{E}=2900$ and $\mathrm{nu}=0.25)$ is stretched at the top $(\mathrm{y}=2)$ with a surface load $\mathrm{g}=\mathrm{n}$ where $\mathrm{n}$ denotes the outer normal to $\partial \Omega$, the rest of the boundary is traction free (12). By reason of symmetry, since, the domain is homogeneous, one will present the quarter of the domain that was discretized. The Dirichlet conditions are $\mathrm{h}=0$ on $[1,2] 0$ and $0[1,2]$ the forces charges are taking as $\mathrm{f}=(0,-(\mu+\lambda))^{t}$ for all nodes with this $\mathrm{f}$ we

\begin{tabular}{|c|c|c|c|}
\hline \multirow[b]{2}{*}{ No. of nodes np } & \multicolumn{3}{|c|}{ Variables } \\
\hline & 80 & 164 & 589 \\
\hline No. of element nt & 130.0000 & 287.00000 & 1099 \\
\hline Step h & 0.3000 & 0.2 .000 & 0.1 \\
\hline $\mathrm{e}_{\mathrm{s}}$ & 0.2252 & 0.20040 & 0.1699 \\
\hline$\|\mathrm{u}-\mathrm{u} h\| 1, \Omega$ with MFEM & 0.0342 & 0.02980 & 0.0146 \\
\hline$\left\|\psi-\psi_{\mathrm{h}}\right\| 0, \Omega$ with MFEM & 0.0567 & 0.03460 & 0.0264 \\
\hline$\llbracket \mathrm{u}-\mathrm{u}\|\| 1, \Omega$ with FEM & 0.4924 & 0.20750 & 0.1448 \\
\hline
\end{tabular}
proposed the exact solution as like as $\mathrm{u}(\mathrm{x}, \mathrm{y})=(\mathrm{xy}$, $\mathrm{xy}+\mathrm{x})$.

The first objectives of the numerical experiment is to test the stability of the divergence of the field of
Table 1: The table showing the different errors

MFEM slope $\alpha=2.082$; FEM slope $\alpha=0.694$

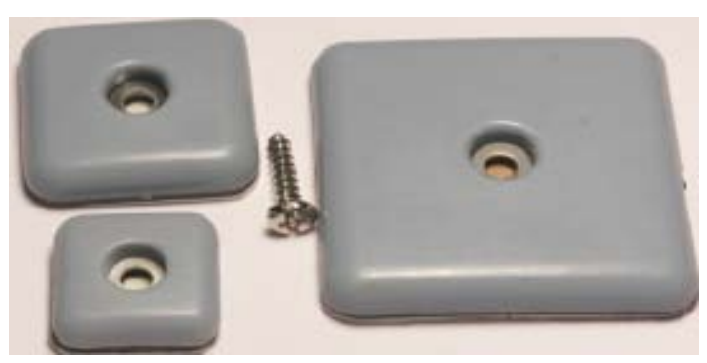

Fig. 1: Square silencing rubber glide with screw and HDPE surface

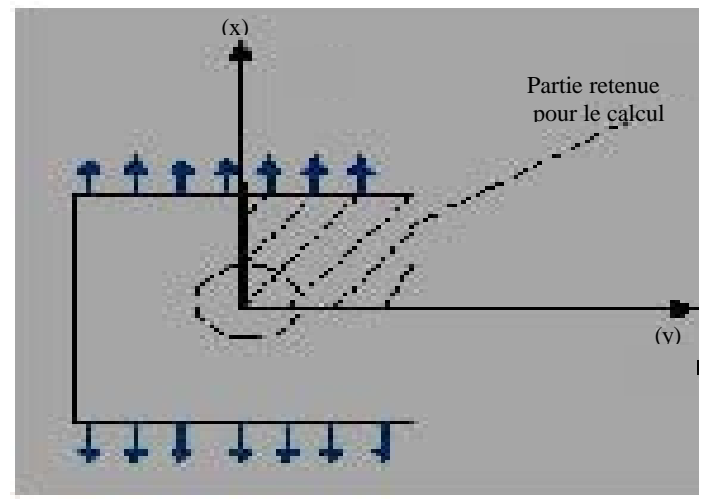

Fig. 2: Square with hole

displacement $\mathrm{u}_{\mathrm{h}}$ numerical solution, in fact we will calculate the error $\mathrm{e}_{\infty}=\max _{\mathrm{i}, \mathrm{j}}\left(\mid \operatorname{divu}\left(\mathrm{x}_{\mathrm{i}}, \mathrm{y}_{\mathrm{i}}\right)\right)-\Psi_{\mathrm{i}, \mathrm{j}}$ for three mesh size grows. That is when $h \rightarrow 0$. So, from the tabular the error $\mathrm{e}_{\infty}$ go to zero when $\mathrm{h}$ is too small. The example demonstrates how the mixed finite element P1 bubble-P1 method is more efficient then the ordinary one. Because, it allows us to calculate the displacements and their divergences simultaneously and that it gurantees the stabilitu of these divergence on each node.

Secondly, we calculate $\left\|\mathrm{u}-\mathrm{u}_{\mathrm{h}}\right\| 1, \Omega$ for each method then we obtain the two slopes by using the linear regression and Table 1 resume all the numerical results (Fig. 1 and 2).

This example shows how to perform simple linear regression using the errors data set. The example also shows you how to calculate the coefficient of determination to evaluate the regressions (Fig. 3-8). 


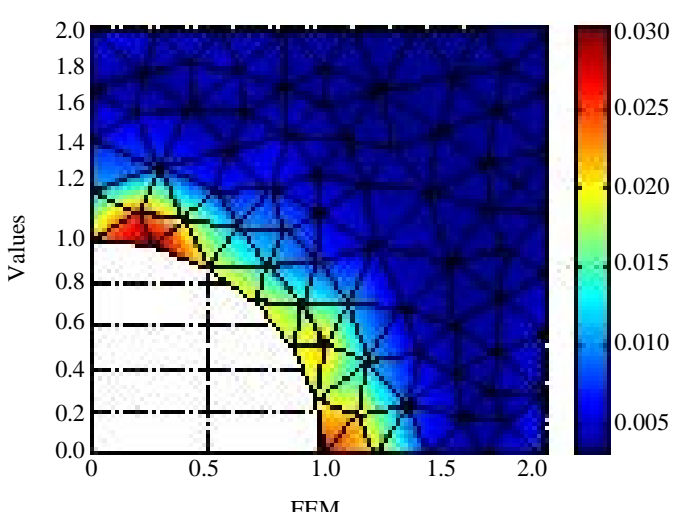

Fig. 3: Deformed mesh for members with hole, case $\mathrm{h}=0.3$ with FEM

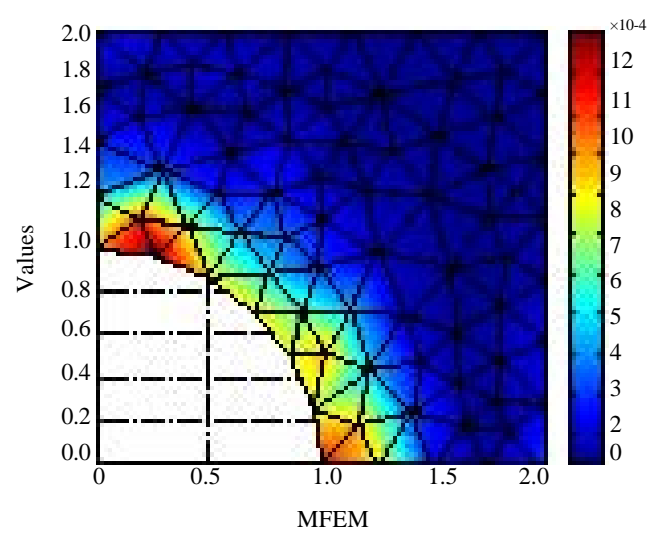

Fig. 4: Deformed mesh for members with hole, case $\mathrm{h}=0.3$ with MFEM

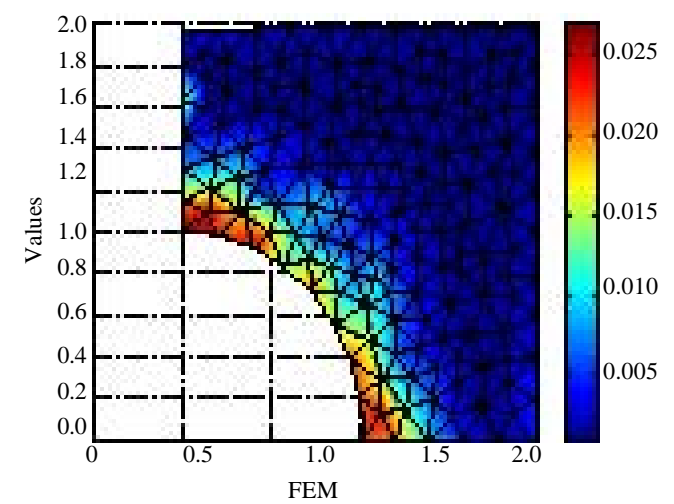

Fig. 5: Deformed mesh for members with hole, case $\mathrm{h}=0.1$ with FEM

Figure 9 and 10 of the linear regression for each methods. Below, we find Table 1 summarizes all the errors that have been calculated and Fig. 3-8 which represent the displacements of the membrane with hole defined above for three steps $h=0,3,0,2,0,1$ for both method MFEM

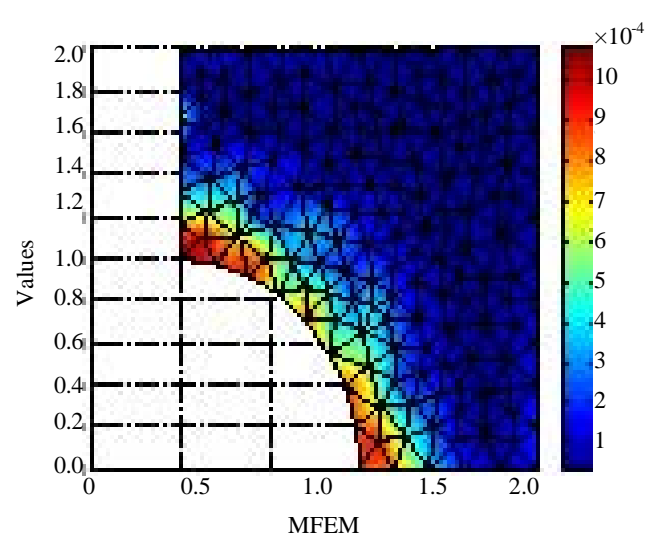

Fig. 6: Deformed mesh for members with hole, case $\mathrm{h}=0.1$ with MFEM

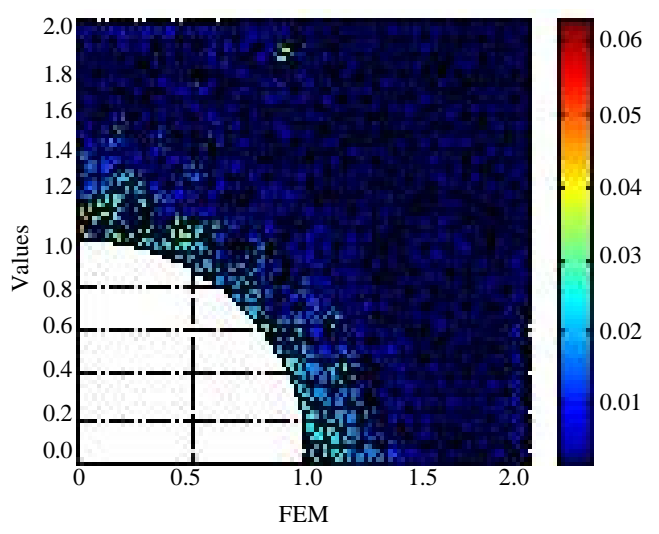

Fig. 7: Deformed mesh for members with hole, case $h=0.1$ with MFEM

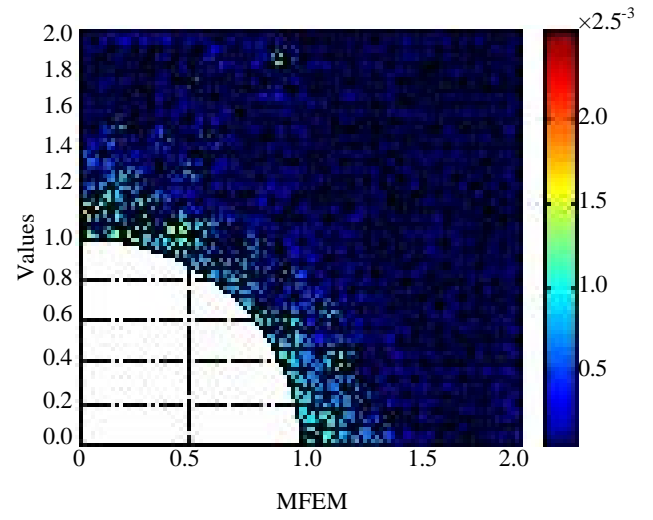

Fig. 8: Deformed mesh for members with hole, case $h=0.1$ with MFEM

and FEM. Figure 9 and 10 represent the linear correlation between $\log \left(\left\|\mathrm{u}-\mathrm{u}_{\mathrm{h}}\right\| 1, \Omega\right)$ and $\log (\mathrm{h})$ with which the speed of convergence has been calculated. 


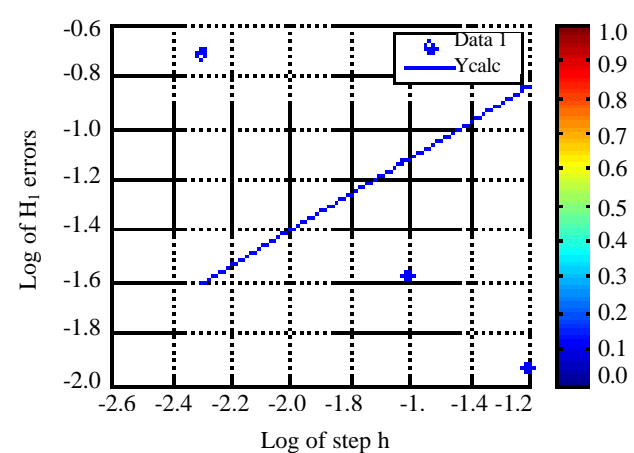

Fig. 9: The slope $\alpha=0.964$ with FEM; Linear regression relation between $\log$ of slope $h$ and $\log$ of $\mathrm{H}_{1}$ errors

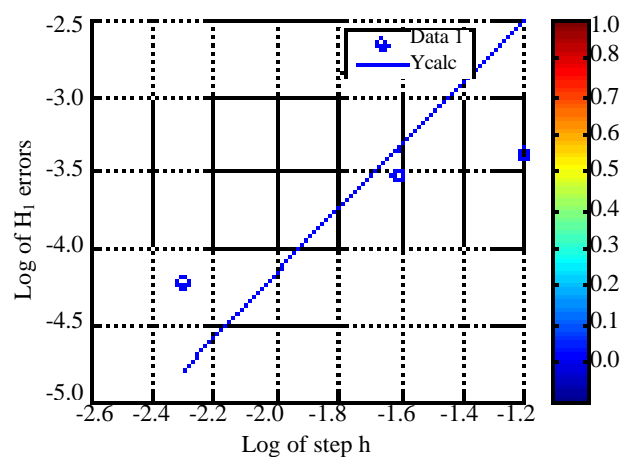

Fig. 10: The slope $\alpha=2.082$ with MFEM; Linear regression relation between $\log$ of slope $\mathrm{h}$ and $\log$ of $\mathrm{H}_{1}$ errors

\section{CONCLUSION}

In this study, we have proposed a mixed finite element P1 bubble-P1 method for solving the system of Navier Lame. A number of reasons have been put to prefer mixed methods over displacement or equilibrium methods in some situations. First of all, equilibrium methods are rarely used in practical computation due to the difficulty of creating finite element spaces incorporating the necessary constraints (the conditions of static admissability and in particular, the equilibrium condition in the case of elasticity). As remarked above for the elasticity problem in which the a form is coercive, stability can always be achieved by adequate enrichment of the displacement space. There are a number of ways to enrich the space. For our example, the unstable pair (linear displacement, linear divergence) element may be stabilized by the addition of a single internal displacement degree of freedom via a bubble (Arnold et al., 1984).

It can be observed from our numerical experiments with the calculation of the slops for each methods, we find that the slope with P1 bubble- P1 method is more superior then the slope with the classical method. This numerical result means that the numerical solution $\mathrm{u}_{\text {spp }}$ obtained by the mixed finite element P1 bubble-P1 method converge very speedy to the exact solution then the other solution obtained by the classical method.

We have demonstrated that for solving the elasticity problem in MATLAB with the mini-element P1 bubble-P1 is much more efficient than a standard implementation with ordinary finite element. Moreover, the advantage of this problem with this new boundary condition is the program level MATLAB. Its enough to do a single program MATLAB and can be reduced to ordinary problems as Dirichlet and Neumann.

\section{RECOMMENDATION}

Further work is underway to derive with the minielement for solving 3D elasticity problems.

\section{ACKNOWLEDGEMENT}

The researchers would like to appreciate the referees for giving us the corrections The researchers declares that there is no conflict of interest regarding the publication of this study.

\section{REFERENCES}

Alberty, J., C. Carstensen, S.A. Funken and R. Klose, 2002. MATLAB implementation of the finite element method in elasticity. Comput., 69: 239-263.

Arnold, D.N., F. Brezzi and M. Fortin, 1984. A stable finite element for the stokes equations. Calcolo, 21: 337-344.

Bathe, K.J., 1996. Finite Element Procedures. Prentice Hall, Upper Saddle River, New Jersey, USA., ISBN: 9780133496970 , Pages: 1037.

Boffi, D., F. Brezzi and M. Fortin, 2013. Mixed Finite Element Methods and Applications. Springer, Berlin, Germany, ISBN:978-3-642-36518-8, Pages: 684.

Brezzi, F. and M. Fortin, 1991. Mixed and Hybrid Finite Element Methods. Springer, Berlin, Germany, ISBN: 9783540975823 , Pages: 350.

Ciarlet Jr. P., J. Huang and J. Zou, 2003. Some observations on generalized saddle-point problems. SIAM. J. Matrix Anal. Appl., 25: 224-236.

EL-Mekkaoui, J., A. Elkhalfi and A. Elakkad, 2013. Resolution of stokes equations with the $\mathrm{Ca}, \mathrm{b}$ boundary condition using mixed finite element method. WSEAS Trans. Math., 12: 586-597. 
Ern, A., 2005. Aide-Memoire Elements Finis. Dunod Publisher, Paris, France, ISBN: 9782100528400 , Pages: 360.

Gatica, G.N., 2014. A Simple Introduction to the Mixed Finite Element Method: Theory and Applications. Springer, Berlin, Germany, ISBN:978-3-319-03694-6, Pages: 130 .

Girault, V. and P.A. Raviart, 1981. Finite Element Methods for Navier-Stokes Equations: Theory and Algorithms. Springer, Berlin, Germany, ISBN:9783540157960, Pages: 376.

Kellogg, R.B. and B. Liu, 1996. A finite elementmethod for the compressible Stokes equations. SIAM. J. Numer. Anal., 33: 780-788.
Koko, J., 2012. Vectorized Matlab codes for the Stokes problem with P1-bubble/P1 finite element. J. Modern Math. Sci., 1: 1-19.

Sadd, M.H., 2005. Elasticity: Theory, Application and Numerics. Elsevier Inc., USA., pp: 229-232.

Timoshoenko, S. and J.N. Goodier, 1985. Theory of Elasticity. 2nd Edn., McGraw-Hall, New York.

Yang, D., 2002. Iterative schemes for mixed finite element methods with applications to elasticity and compressible flow problems. Numerische Mathematik, 93: $177-200$.

Zienkiewicz, O.C., R.L. Taylor and J.Z. Zhu, 2013. The Finite Element Method: Its Basis and Fundamentals. 7th Edn., Elsevier, New York, USA., ISBN:978-1-85617-633-0, Pages: 714. 